\title{
Acute trophoblastic pulmonary embolism during conservative treatment of placenta accreta: case report and review of literature
}

\author{
Qiu-ming Wang ${ }^{1}$, Hui-li Liu ${ }^{2 *}$ and Qun Dang ${ }^{2}$
}

\begin{abstract}
Background: Placenta accreta is a rare obstetric condition but can lead to life-threatening complications that was mainly diagnosed in the third trimester. We present a case of acute trophoblastic pulmonary embolism (PE) during conservative treatment of placenta accreta.
\end{abstract}

Case presentation: A 24-year-old patient who delivered vaginally at $40^{+4}$ weeks gestation. The placenta was retained despite the use of oxytocics and attempts of manual removal. Conservative management including uterine arteria embolism, hysteroscopic resection and mifepristone was used but failed and finally the patient died from acute trophoblastic PE and allergic shock when infusing povidone-iodine into her uterine cavity.

Conclusion: Although conservative treatment of placenta accreta can retain reproductive potential and trophoblastic PE is rare, clinicians should consider hysterectomy when conservative treatment failed and infusion of povidoneiodine or other liquid into the cavity should be prohibited.

Keywords: Trophoblastic pulmonary embolism, Allergic shock, Placenta accreta, Conservative treatment

\section{Background}

Placenta accreta indicates deep attachment of the placenta to myometrium due to the absence of decidua basalis [1]. The optimal management of this condition remains controversial. Although hysterectomy is a choice for retained placenta, leaving the placenta in situ with conservative treatment such as uterine arteria embolism, mifepristone, methotrexate and hysteroscopic resection can also be undertaken when there is no hemorrhage and the patient want to preserve her fertility. Conservative management also has some risk such as hemorrhage, infection, failure and subsequent hysterectomy, and even death [2].

We present a unique case of death caused by acute trophoblastic PE and anaphylactic shock during

\footnotetext{
*Correspondence: liuhuili72@sohu.com

${ }^{2}$ Department of Gynecology, Henan Provincial People's Hospital,

Zhengzhou 450000, China

Full list of author information is available at the end of the article
}

conservative treatment of placenta accreta. To our knowledge, this is the first report about trophoblastic PE during conservative management of placenta accreta.

\section{Case presentation}

A woman with a history of one spontaneous miscarriage of 7-week gestation without curettage or other treatment had a vaginal delivery at $40^{+4}$ weeks gestation. The placenta was retained in the cavity despite the use of oxytocics. Manual removal of the placenta was attempted, but unsuccessful. Emergency ultrasound scan revealed placenta tissue measuring $165 \times 130 \times 94 \mathrm{~mm}^{3}$ without a clear boundary with myometrium. Magnetic resonance imaging (MRI) confirmed placenta accreta the next day (Fig. 1). Her pre-delivery hemoglobin concentration was $11.9 \mathrm{~g} / \mathrm{dL}$ and the estimated blood loss was $200 \mathrm{~mL}$ without active hemorrhage. She wanted to keep her uterus and declined hysterectomy, so uterine arterial embolism was performed in case of massive hemorrhage. After 


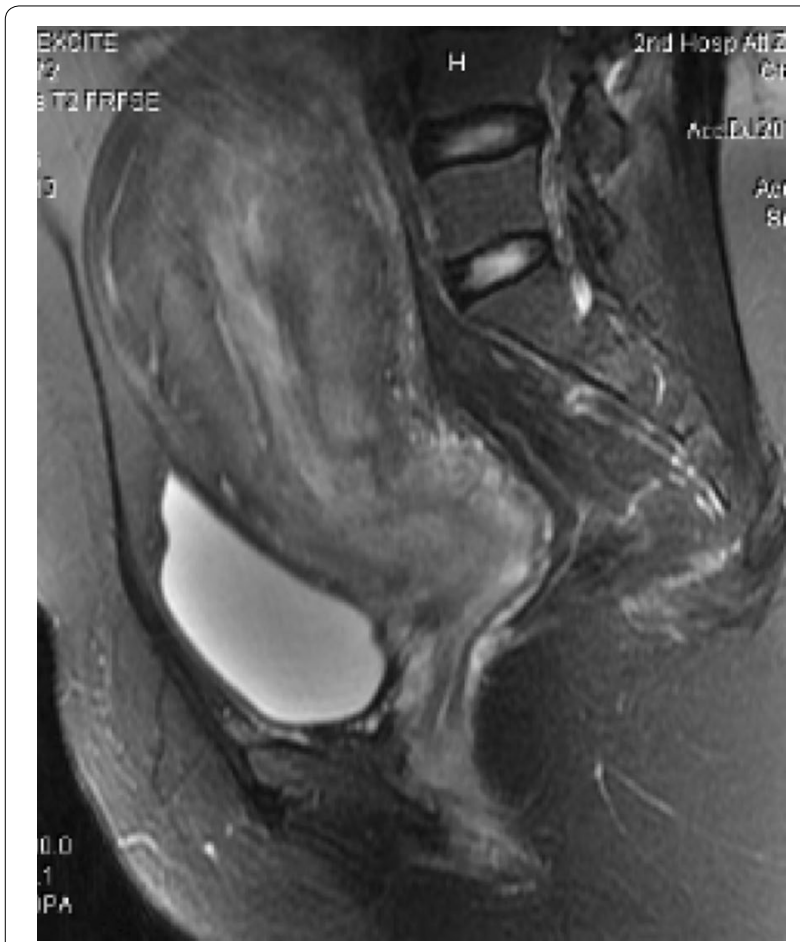

Fig. $1 \mathrm{MRI}$ demonstrates segment of placenta extending outside of the visible myometrium

embolization, her general condition was fine except mild pelvic pain. Prophylactic intravenous injections of Cefazolin Sodium Pentahydrate $1.0 \mathrm{~g}$ and Ornidazole $0.5 \mathrm{~g}$, 12 hourly were used to decrease the chance of infection. 3 days later her body temperature raised to $38.3^{\circ} \mathrm{C}$, laboratory result on $\mathrm{C}$ reactive protein was $>200 \mathrm{mg} / \mathrm{L}$ and white blood cell count was $18.5 \times 10^{9} / \mathrm{L}$. Escherichia coli was isolated from vagina secretion. Conservative treatment needed to be abandoned but she still declined hysterectomy. Cefazolin Sodium Pentahydrate was changed to Cefoperazone-Sulbactam $3 \mathrm{~g}, 12$ hourly according to the drug-sensitive test. Her general condition became better and she was transferred to gynecology. To accelerate the placenta elimination, hysteroscopic resection was undertaken 9 days after her delivery. Placenta could be seen everywhere in the cavity from the hysteroscope. The surgery had to terminated $90 \mathrm{~min}$ later to avoid water intoxication. About $6 \times 6 \times 1 \mathrm{~cm}^{3}$ of placenta was resected. Mifepristone was used $25 \mathrm{mg}$ orally daily to promote necrosis of trophoblastic as her serum $\beta$-hCG was still $2608 \mathrm{mIU} / \mathrm{ml}$. The next day after hysteroscopy her body temperature raised to $40.3{ }^{\circ} \mathrm{C}$. Blood culture was negative but Escherichia coli could still be found in vagina secretion. Antibiotics were changed to Amikacin $0.6 \mathrm{~g} \mathrm{q} 12 \mathrm{~h}$ and Cefoxitin $2.0 \mathrm{~g}$ q8 h according to drugsensitive test. Purulent secretion and necrotic tissue can be seen in the cervix and cavity during gynecological examination. Povidone-iodine was infused into her cavity to wash out the purulent secretion and necrotic tissue with a double cavity flexible pip with her permission. During this procedure, the second time the patient immediately experienced dyspnea and lost consciousness soon after about $15 \mathrm{~mL}$ povidone-iodine was infused into her cavity. The clinical picture suggested acute respiratory distress syndrome. Cardiopulmonary resuscitation was performed immediately. However, despite all efforts, the patient died. Written consent was obtained from her relatives and autopsy was performed to investigate the underlying pathological condition. Autopsy revealed that trophoblastic PE (Fig. 2) and anaphylactic shock (Fig. 3) were the causes of her death.

\section{Discussion}

Commonly risk factors for placenta accreta are previous cesarean section, dilatation and curettage, placenta previa, previous uterine injury or surgery [3]. As the cesarean section rate and artificial abortion rates are rising, the placenta accreta rate is also increasing [4], especially in China. In some part of mainland China, the cesarean section rate is as much as $54.9 \%$, the highest in the world [5]. In contrast to many reports, our patient had no risk factor mentioned above.

Ultrasound and MRI have been described to diagnose placenta accreta in literature. However, prenatal diagnosis of placenta accreta remains a challenge. Most of placenta accreta was diagnosed in the third stage of labor [6]. One prospective population-based study of women diagnosed with placenta accreta found that only less than $50 \%(66 / 133)$ were suspected antenatally. Antenatally diagnosis of placenta accreta reduced the ratio of

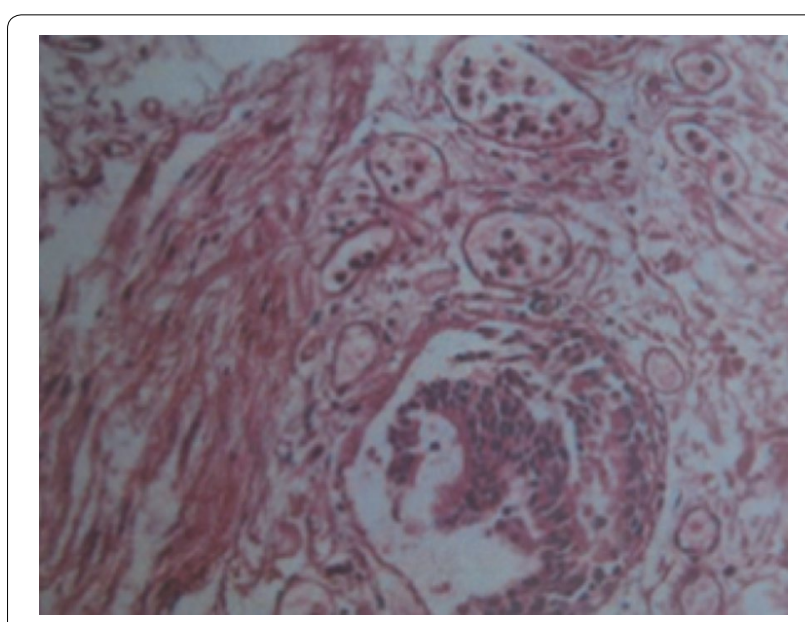

Fig. 2 Histopathological picture showing that trophoblastic emboli can be found in the pulmonary interstitial vessels 


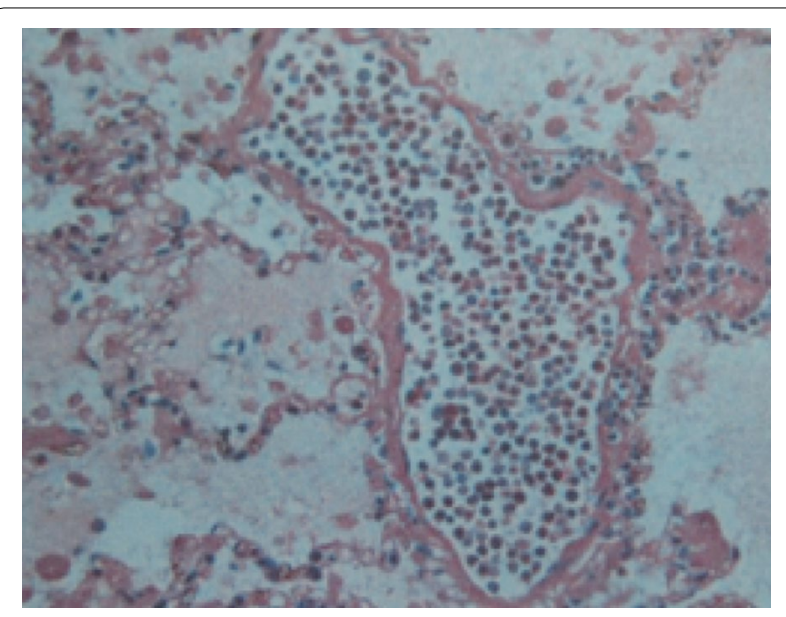

Fig. 3 Histopathological picture showing that a lot of eosinophils can be found in pulmonary interstitial vessels

hemorrhage and blood transfusion with statistical significance. So antenatally diagnosis is very important for placenta accreta [7]. In our case, prenatal ultrasound also did not diagnose the placenta accreta.

Placenta accreta morbidity is mainly caused by hemorrhage, especially when surgical attempts are used to remove the placenta, which can cause intraoperative and postoperative maternal morbidity, large-volume blood transfusions, ureteral damage, intraabdominal infection [2]. So surgical attempts to remove placenta should be avoided when placenta accreta is suspected. The options for managing placenta accreta include hysterectomy and conservative treatment. If the placenta accreta was diagnosed before delivery or during cesarean section, cesarean hysterectomy is generally considered the standard treatment for placenta accreta. Subsequent hysterectomy after vaginal delivery is also appropriate when massive hemorrhage is threatening life. Conservative treatment may be applied for some women who want to keep their uterus when there is no hemorrhage.

There is no standard conservative treatment option for placenta accreta. Conservative treatment includes uterine artery embolization, methotrexate, mifepristone and hysteroscopic resection. Uterine artery catheterization can reduce risk of massive hemorrhage in the management of placenta accreta [8]. Methotrexate has been used to promote the necrosis and resorption of placenta. However, methotrexate has some serious side effects, women unable to breastfeed and a maternal death related to the use of methotrexate has been reported [2]. Royal College of Obstetricians and Gynaecologists noted that methotrexate has little benefit in enhancing placental resorption [9]. Mifepristone has been successfully used in placenta accreta without any complication
[10]. Leaving the placenta in situ after delivery can delay placental expulsion or resorption for weeks or even months. Resection of persistent retained placenta tissue by hysteroscopy can shorten this period and reduce the risk for infection and bleeding [11]. One large series on the conservative treatment of placenta accreta includes uterotonic drugs (oxytocin or sulprostone or both), prophylactic antibiotic therapy, methotrexate, pelvic arterial embolization. The success rate of this study was $78.5 \%$ $(131 / 167)$ and the remaining 36 women had hysterectomy [2]. In our case, although three conservative treatments were applied to her, the serum $\beta$-hCG was still $2890 \mathrm{mIU} / \mathrm{mL}$ before death. Her body temperature and laboratory result suggested she got an infection. Those indicate that conservative treatments were not appropriate for her and hysterectomy should be applied immediately but she declined.

$\mathrm{PE}$ is defined as embolisation to the pulmonary circulation by thrombus, adipocytes, amniotic fluid, tumor, bacteria, or gas, but trophoblastic tissue is very rare. Unlike other kind of embolus, the presence of trophoblastic tissue in the maternal circulation is not considered abnormal [12]. Between 30 and $80 \%$ of obstetric patients have trophoblastic cells in their peripheral circulation. However, the quantity of trophoblastic tissue found in pulmonary vessels indicates that trophoblastic PE led to maternal death. The diagnosis of trophoblastic PE is based on both clinical information and pathological outcomes [13]. Ikarashi et al. [14] identified two histopathological patterns of trophoblastic PE: one composed of intact trophoblastic cells similar to those seen in chorionic villi and identified easily by H\&E staining; the other consisted of amorphous and fragmented trophoblastic cells that were more difficult to identify by routine staining.

Trophoblastic PE was first described by Schmorlin 1893 in a postmortem study of eclamptic patients [15]. Most of trophoblastic PE happens in gestational trophoblastic disease, during cesarean section and curettage. Garner et al. [16] report on trophoblastic PE in a young woman following abdominal hysterectomy for invasive gestational trophoblastic disease. Fortunately, she got complete recovery after $72 \mathrm{~h}$ with the treatment of supportive measures. Tews et al. [13] report on sudden death in a young woman following cesarean section and histological investigation revealed trophoblastic cells within the lumen of small-sized pulmonary vessels and thought that microscopic injuries during decompression punctures might have favored the deportation of trophoblastic tissue into the maternal circulation. Seiryu et al. [17] report on trophoblastic PE in a young woman during the curettage procedures of 7-week gestation and thought that the trophoblastic PE was caused by direct 
access of trophoblastic tissues to the uterine veins draining the maternal intervillous space during the curettage procedures.

To our knowledge, this is the first case of trophoblastic PE to occur during conservative treatment of placenta accreta. The pathogenesis of emboli is far more complex than mechanical obstruction of vascular, especially nonthrombotic emboli. Nonthrombotic emboli such as trophoblastic cells may also lead to a severe inflammatory reaction [18]. In our case, anaphylactic shock also accompanied the trophoblastic PE.

Povidone-iodine is commonly used in infectious wound. We infused povidone-iodine into her cavity with the purpose of washing out necrotic tissue and purulent secretion to reduce infection. There was no active hemorrhage so we did not predict that povidone-iodine or some other things could get into her circulation. May be the reason for trophoblastic PE was that as three conservative treatments had been applied to her, the retained placenta is necrotic and loosely adhered to the myometrium. The sudden introduction of povidone-iodine may have detached part of the placenta and exposing a blood vessel; the trophoblastic cells entered the blood circulatory system and the trophoblastic PE happened. Therefore, infusion of povidone-iodine or some other liquid to the cavity during conservative treatment of placenta accreta should be avoided.

\section{Conclusion}

We present a unique case of acute trophoblastic PE during conservative treatment of placenta accreta in a 24-year-old female. Careful evaluation of this rare complication and painful lesson may provide us some experience in the treatment of placenta accreta. This case reminds us that hysterectomy should be employed when conservative treatment of placenta accreta fails to avoid severe complications. Infusion of povidone-iodine or other liquid to the uterine cavity during conservative treatment of placenta accreta should be avoided.

\section{Consent}

Written informed consent was obtained from the patient for publication of this Case report and any accompanying images. A copy of the written consent is available for review by the Editor-in-Chief of this journal.

\section{Abbreviations}

PE: pulmonary embolism; MRI: magnetic resonance imaging.

\section{Authors' contributions}

All authors participated in the preparation of the manuscript. QMW collected all clinical data. All authors read and approved the final manuscript.

\section{Author details}

'Department of Gynecology, The Second Affiliated Hospital of Zhengzhou University, Zhengzhou 450000, China. ${ }^{2}$ Department of Gynecology, Henan Provincial People's Hospital, Zhengzhou 450000, China.

\section{Acknowledgements}

The authors acknowledge the contribution of Dr Gen-hong Mao for his insight. There was no funding for the present study.

\section{Competing interests}

The authors declare that they have no competing interests.

Received: 31 May 2015 Accepted: 15 October 2015

Published online: 14 November 2015

\section{References}

1. Adler E, Madankumar R, Rosner M, et al. Increased placental trophoblast inclusions in placenta accreta[J]. Placenta. 2014;35(12):1075-8.

2. Sentilhes $L$, Ambroselli $C$, Kayem $G$, et al. Maternal outcome after conservative treatment of placenta accreta[J]. Obstet Gynecol. 2010;115(3):526-34

3. Fitzpatrick KE, Sellers S, Spark P, et al. Incidence and risk factors for placenta accreta/increta/percreta in the UK: a national case-control study[J]. PLoS One. 2012;7(12):e52893.

4. Ac W, Jm A. Placenta accreta, increta, and percreta.[J]. Obstet Gynecol Clin North Am. 2013:40(1):137-54.

5. Liu Y, Li G, Chen Y, et al. A descriptive analysis of the indications for caesarean section in mainland China[J]. BMC Pregnancy Childbirth. 2014;14(1):410

6. Bauwens J, Coulon C, Azaïs H, et al. Placenta accreta: can prenatal diagnosis be performed? Ultrasound and MRI interests. About 27 cases[J]. Gynecol Obstet Fertil. 2014;42(5):306-11.

7. Fitzpatrick KE, Sellers S, Spark P, et al. The management and outcomes of placenta accreta, increta, and percreta in the UK: a population-based descriptive study[J]. BJOG Int J Obstet Gynaecol. 2014;121(1):62-71.

8. Gustavo I, César M, Mario G, et al. Feasibility and safety of prophylactic uterine artery catheterization and embolization in the management of placenta accreta.[J]. J Vasc Interv Radiol Jvir. 2015;26:162-9.

9. RoyalCollegeofObstetriciansandGynaecologists.Green-top Guideline No. 27. Placenta praevia, placenta praevia accreta and vasa praevia: diagnosis and management. London: RCOG; 2011.

10. Morgan M, Atalla R. Mifepristone and misoprostol for the management of placenta accreta-a new alternative approach[J]. BJOG Int J Obstet Gynaecol. 2009;116(7):1002-3.

11. Legendre G, Zoulovits FJ, Kinn J, et al. Conservative management of placenta accreta: hysteroscopic resection of retained tissues[j]. J Minim Invasive Gynecol. 2014;21(5):910-3.

12. Mueller UW, Hawes CS, Wright AE, et al. Isolation of fetal trophoblast cells from peripheral blood of pregnant women.[J]. Lancet. 1990;336:197-200.

13. Tews $G$, Yaman $C$, Ebner T. Fatal trophoblastic embolism during cesarean section[J]. Int J Gynecol Obstet. 2002;76(2):179-80.

14. Ikarashi T, Takeuchi S, Ohnishi Y. Trophoblastic embolism in sudden maternal death[J]. Nihon Sanka Fujinka Gakkai zasshi. 1988;40(6):793-5.

15. Schmorl G. Pathologisch-anatomische Untersuchungen uber PeerperalEklampsie. Leipzig: Vogel; 1893

16. Garner El, Chang-Lee WY, Lu KH, et al. Trophoblastic pulmonary embolization after hysterectomy for invasive complete mole. A case report. J Reprod Med. 1999;44:908-12.

17. Seiryu K, Yoshiharu O, Osamu M, et al. Placental villotrophoblastic pulmonary emboli. After elective abortion: immunohistochemical diagnosis and comparison with ten control cases[J]. Int J Gynecol Pathol. 2003:22(3):303-9.

18. Jorens PG, Van Marck E, Snoeckx A, et al. Nonthrombotic pulmonary embolism[J]. Eur Respir J. 2009;34(2):452-74. 